\title{
REDUÇÃO DA INFESTAÇÃO DE BRACHIARIA PLANTAGINEA EM SOJA PELA COBERTURA DO SOLO COM PALHA DE AVEIA-PRETA ${ }^{1}$
}

\author{
GIOVANI THEISEN ${ }^{2}$, RIBAS ANTONIO VIDAL ${ }^{3}$ e NILSON GILBERTO FLECK ${ }^{3}$
}

\begin{abstract}
RESUMO - Este trabalho foi conduzido em área da Universidade Federal do Rio Grande do Sul, em Eldorado do Sul, RS, em 1996/97, com o objetivo de avaliar os efeitos de resíduos de aveia-preta (Avena strigosa Schreb.) sobre o solo na densidade de papuã (Brachiaria plantaginea (Link) Hitch.) e no rendimento da cultura da soja (Glycine max L. Merrill). O experimento foi conduzido em delineamento de blocos casualizados em parcelas subdivididas, com quatro repetições; os tratamentos método de controle de papuã (nas parcelas) e cobertura do solo (nas subparcelas) foram arranjados em esquema fatorial. A densidade da planta daninha diminuiu de forma exponencial com o aumento da cobertura de aveia sobre o solo, variando de 829 a 86 plantas $/ \mathrm{m}^{2}$ para níveis de cobertura $0,0 \mathrm{t} / \mathrm{ha}$ e $10,5 \mathrm{t} / \mathrm{ha}$, respectivamente. Houve maior infestação de papuã nas linhas do que nas entrelinhas da cultura. Não houve efeito da cobertura vegetal no rendimento da soja quando a cultura foi mantida livre de papuã. Por sua vez, níveis crescentes de resíduos vegetais sobre o solo controlaram papuã e aumentaram linearmente o rendimento da cultura. Nas condições de alta infestação da área, a produção de grãos aumentou na razão de $158 \mathrm{~kg} / \mathrm{ha}$ de grãos por tonelada de palha sobre o solo.
\end{abstract}

Termos para indexação: papuã, planta daninha, plantio direto, resíduos vegetais, Glycine max, Avena strigosa.

\author{
REDUCTION OF BRACHIARIA PLANTAGINEA INFESTATION \\ ON SOYBEAN CROP WITH BLACK OAT RESIDUES
}

\begin{abstract}
This work was conducted at Universidade Federal do Rio Grande do Sul, in Eldorado do Sul, Rio Grande do Sul State, Brazil, during 1996/97, to evaluate the effect of black oats (Avena strigosa Schreb.) residues on alexandergrass (Brachiaria plantaginea (Link) Hitch.) density and on soybean (Glycine max L. Merrill) yield. Treatments were arranged in split-plot in a randomized complete block design with four replicates, with weed control method as main plots and level of black oat residues as subplots. An exponential reduction of alexandergrass density was observed, with data varying from 829 to 86 plants $/ \mathrm{m}^{2}$ for levels of straw on the soil surface of 0 to 10.5 ton/ha, respectively. Higher weed infestation occurred on the crop row than between the rows. In the weed-free treatments, soybean yield was not affected by crop residues. On the other hand, soybean yield increased linearly with increased amount of black oat residues on the soil controlling the weed. In weedy areas, soybean yield increased at the rate of $158 \mathrm{~kg} / \mathrm{ha}$ for each ton of straw on the soil surface.
\end{abstract}

Index terms: no-till, weed, crop residues, Glycine max, Avena strigosa, alexandergrass.

\section{INTRODUÇÃO}

Nas últimas décadas houve incremento na adoção de sistemas conservacionistas de produção

\footnotetext{
${ }^{1}$ Aceito para publicação em 12 de maio de 1999.

${ }^{2}$ Eng. Agrôn., M.Sc., aluno do Programa de Pós-Graduação da UFRGS, Caixa Postal 776, CEP 90001-970 Porto Alegre, RS.

${ }^{3}$ Eng. Agrôn., Ph.D., Fac. de Agronomia, UfRGS. Bolsista do CNPq. E-mail: vidal@ifl.if.ufrgs.br
}

agrícola, os quais têm como principais características o reduzido revolvimento do solo, aliado à manutenção de resíduos das culturas sobre a superfície. Além de proteger o solo contra a erosão, a manutenção da cobertura vegetal reduz a infestação de gramíneas anuais na cultura da soja (Vidal \& Bauman, 1996; Voll et al., 1996). Resíduos de aveia-preta (Avena strigosa Schreb.) e aveia-branca (Avena sativa) controlam a infestação de papuã (Brachiaria plantaginea (Link) Hitch.) na cultura da soja (Roman, 1990), possivelmente por diminuírem a dormência das sementes (Theisen, 1998). 
Entre as plantas daninhas presentes nas culturas de verão, papuã é a gramínea de maior incidência, sendo encontrada em $62 \%$ das áreas do Planalto do Rio Grande do Sul. Também pode ser verificada na maioria das áreas com culturas de verão, em diversos locais no Brasil, causando prejuízos consideráveis ao rendimento e qualidade da produção (Kissmann, 1991; Fleck, 1996). Infestações de papuã na cultura da soja diminuem seu rendimento, e analisando-se dados acumulados em diversos anos de pesquisas, constata-se que densidades variáveis entre 70 e 780 plantas $/ \mathrm{m}^{2}$ geram perdas na produtividade da soja entre 18\% e 82\% (Fleck, 1996).

O objetivo deste estudo foi determinar os efeitos da cobertura vegetal de aveia-preta na infestação de papuã, bem como seu impacto no rendimento da cultura de soja.

\section{MATERIAL E MÉTODOS}

O experimento foi conduzido durante o ano agrícola 1996/97, na Estação Experimental Agronômica da UFRGS, em Eldorado do Sul, RS. O solo do local é classificado como Podzólico Vermelho-Escuro distrófico (Pauledult) (Espírito Santo, 1988).

Utilizou-se delineamento em blocos casualizados com parcelas subdivididas, com quatro repetições. As parcelas principais foram os níveis de cobertura vegetal sobre o solo $(0,0,2,6,5,2,7,8$ e $10,5 \mathrm{t} / \mathrm{ha}$ de matéria seca) e as subparcelas, os métodos de controle de papuã (com e sem controle químico). Cada subparcela consistiu de uma área com $10 \mathrm{~m}^{2}$ (5 m x $\left.2 \mathrm{~m}\right)$, sendo cada bloco composto por 10 parcelas.

A cobertura do solo utilizada foi palha de aveia-preta dessecada com os herbicidas glyphosate $+2,4-\mathrm{D}$ amina $(0,7+0,5 \mathrm{~kg} / \mathrm{ha}$ de i.a. $)$, cortada após a semeadura da soja, quando então se ajustaram os níveis conforme os tratamentos.

Nas parcelas com controle químico, as gramíneas foram controladas com clethodim (Select $240 \mathrm{CE}$ ), a $120 \mathrm{~g} / \mathrm{ha}$ de i.a., $+0,5 \%$ v.v. de óleo mineral. As poucas plantas daninhas dicotiledôneas foram controladas manualmente. A soja (cultivar Ocepar-14) foi semeada em 7/11/96, na densidade de 38 plantas $/ \mathrm{m}^{2}$, em linhas com espaço entre si de $50 \mathrm{~cm}$, utilizando-se sistema de semeadura direta. Procedeu-se a inoculação de Bradyrizhobium japonicum nas sementes de soja, e todos os tratamentos receberam adubação do solo com $60 \mathrm{~kg} / \mathrm{ha}$ de $\mathrm{P}_{2} \mathrm{O}_{5}$ e de $40 \mathrm{~kg} / \mathrm{ha}$ de $\mathrm{K}_{2} \mathrm{O}$.

Aos 50 dias após a semeadura, foi avaliada a densidade de papuã na linha e nas entrelinhas da soja, posicionan- do-se um quadro metálico com $0,1 \mathrm{~m}^{2}(0,10 \times 1,0 \mathrm{~m})$ no solo, sobre e entre as duas linhas centrais de cultivo, respectivamente. A densidade foi determinada mediante contagem das plantas, nos tratamentos onde se utilizou apenas cobertura vegetal para suprimir a planta daninha. A colheita da soja foi realizada aos 151 dias após a emergência nas duas linhas centrais de cultivo de cada parcela, e o seu rendimento determinado com base em umidade padrão de $13 \%$.

Os resultados obtidos foram testados por análise de variância, com teste $\mathrm{F}$ a $5 \%$ de probabilidade, sendo complementados pelo teste de Tukey a $5 \%$, e por análise de correlação entre a densidade de papuã e o rendimento de grãos da cultura. Para complementar a interpretação das figuras, foi utilizado o procedimento sugerido por Browne (1979), por comparação do erro-padrão das médias.

\section{RESULTADOS E DISCUSSÃO}

A análise de variância não indicou interação entre os fatores nível de palha e controle de papuã, mas somente efeito individual dos mesmos na densidade de plantas. A infestação de papuã (Y) foi reduzida de forma exponencial com o incremento dos níveis de palha de aveia (X) sobre o solo, independentemente de seu posicionamento (na linha ou entrelinha) junto à cultura (Fig. 1). Esses resultados concordam com os obtidos por Theisen (1998) em experimentos similares em áreas sem cultura. Constatou-se que camadas de palha de até 10,5 t/ha não impedem o sucesso no estabelecimento de plantas de papuã em área cultivada com soja (Fig. 1), ou mesmo em área sem cultivo (Theisen, 1998).

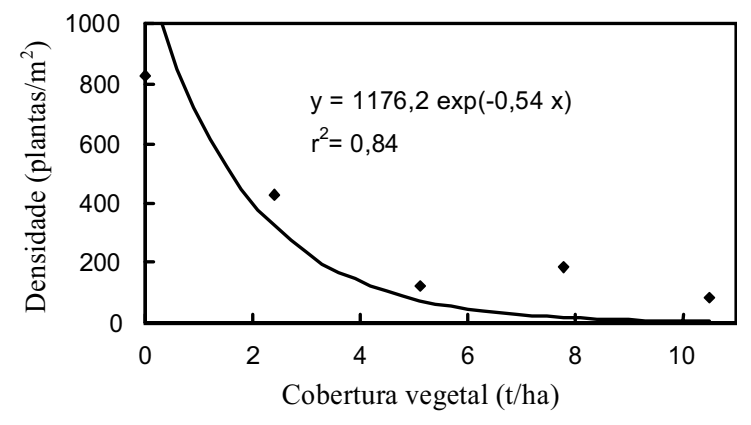

FIG.1. Densidade de Brachiaria plantaginea em cinco níveis de cobertura do solo, na média de avaliações realizadas na linha e entrelinha da cultura da soja, aos 50 dias após a emergência. EEA/UFRGS, Eldorado do Sul, RS, 1997. 
Na média dos níveis de palha houve menor infestação de papuã na entrelinha (252 plantas $\left./ \mathrm{m}^{2}\right)$ do que na linha (410 plantas $\left./ \mathrm{m}^{2}\right)$ da cultura da soja. Para cada nível de cobertura sobre o solo, a população emergente na linha foi superior à das entrelinhas, possivelmente pelo revolvimento do solo na linha de cultivo durante a semeadura. É provável que nesse período sementes viáveis localizadas em camadas mais profundas tenham sido trazidas para a superfície.

Solos sem cobertura vegetal apresentam geralmente maior amplitude térmica diária do que solos protegidos (Salton \& Mielnickzuk, 1995). Sob solo desnudo, as sementes de papuã próximas da superfície sofrem efeito térmico acentuado, passando rapidamente, e em maior número, de dormentes para quiescentes, permanecendo assim aptas à germinação (Theisen, 1998). Outra possível explicação para a reduzida densidade de $B$. plantaginea em solos com cobertura, seria a redução da quantidade e modificação da qualidade da luz que atinge as sementes desta espécie nos solos com palha na superfície.

Observou-se interação entre cobertura do solo e métodos de controle de papuã no rendimento de grãos de soja. O tratamento com controle químico apresentou rendimento semelhante nos diversos níveis de palha $(\mathrm{P}>0,05)$, com produtividade média de $4.002 \mathrm{~kg} /$ ha (Fig. 2).

Quando a invasora não foi controlada quimicamente na cultura, maiores níveis de cobertura vegetal sobre o solo aumentaram o rendimento de soja (Fig. 2). Porém, mesmo baixas infestações de papuã, como foi observado quando se utilizou o nível máximo de cobertura vegetal, podem ser prejudiciais a longo prazo. Nesse caso, as plantas sobreviventes podem produzir sementes em quantidade suficiente para reabastecer o banco no solo, dando continuidade às infestações futuras.

Incremento linear observado no rendimento de soja foi atribuído à redução da infestação de papuã, em resposta aos níveis crescentes de cobertura sobre o solo. O rendimento de grãos de soja aumentou $158 \mathrm{~kg} /$ ha para cada tonelada de palha na superfície do solo (Fig. 2), enquanto a população de papuã decresceu de forma exponencial (Fig. 1).

A elevada associação entre a população de papuã e o rendimento de grãos de soja confirma a hipótese de que o incremento do rendimento da cultura com o aumento dos níveis de palha sobre o solo (Fig. 3) deve-se à redução da infestação de papuã pela palha. Quando o número de plantas de papuã foi baixo, pequenos incrementos em sua densidade diminuíram o rendimento da cultura de forma aditiva (Fig. 3). Quando a densidade foi alta, a redução do rendimento foi menos pronunciada do que no caso anterior. Tal comportamento representa o padrão logístico negativo (Zullo Júnior \& Arruda, 1986), que pode ser decomposto em duas retas (Cousens, 1985), como indicado na Fig. 3.

Para densidades de papuã de até 603 plantas $/ \mathrm{m}^{2}$, cada planta da invasora reduziu o rendimento de grãos de soja em $4,45 \mathrm{~kg}$ ou o equivalente a $0,1 \%$ do rendimento. Densidades superiores a 603 plantas $/ \mathrm{m}^{2}$ não afetaram tão acentuadamente o rendimento de grãos de soja, e causaram perda de $0,33 \mathrm{~kg}$ de grãos por planta adicional de papuã (Fig. 3). Segundo Stoller et al. (1987), tal fato provavelmente ocorre pela sobreposição das áreas de influência de cada planta daninha e subseqüente redução do seu impacto na soja.

Considerando que nos últimos três anos o preço médio da soja foi de R $\$ 170,00 /$ t, e o custo médio de controle químico de gramíneas de $\mathrm{R} \$ 25,00 /$ ha, para densidades de até 603 plantas $/ \mathrm{m}^{2}$ cada planta de

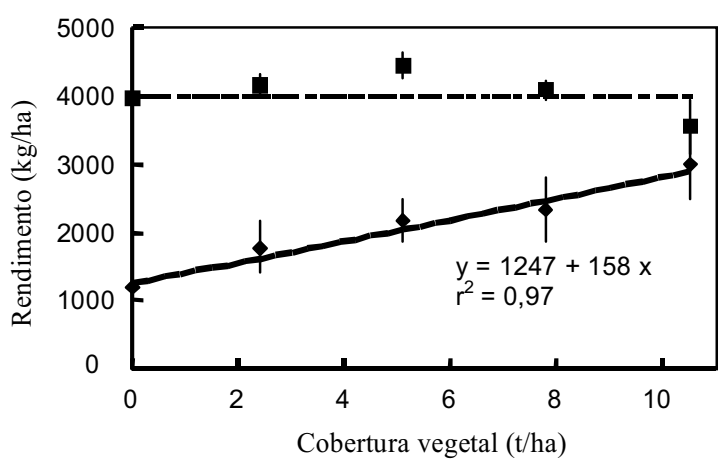

FIG. 2. Rendimento de grãos de soja cultivada sob cinco níveis de cobertura vegetal e método químico ( $\square$ ) e cultural $(\nabla)$ de controle de Brachiaria plantaginea. EEA/UFRGS, Eldorado do Sul, RS, 1997. (Barras representam 0 erro-padrão da média; linha pontilhada e cheia representam a média de rendimento nos tratamentos químico e cultural, respectivamente.) 


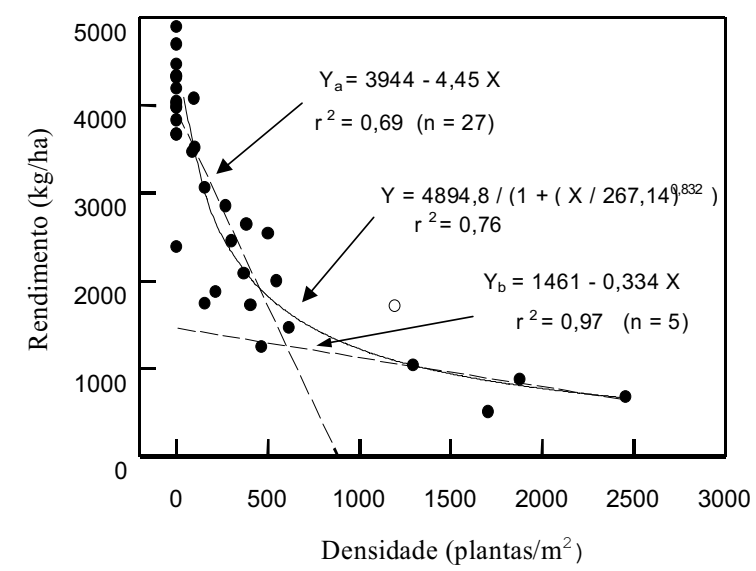

FIG.3. Rendimento de grãos de soja em função da densidade de Brachiaria plantaginea. EEA/UFRGS, Eldorado do Sul, RS, 1997. (Símbolo vazio indica outlier; $\mathrm{Y}_{\mathrm{a}}$ elaborada com densidades até 618 plantas de papuã; $\mathrm{Y}_{\mathrm{b}}$ elaborada com os dados dos 5 menores rendimentos de soja).

papuã pode representar a perda de $\mathrm{R} \$ 0,76$. Assim, o nível de dano econômico, ou seja, a densidade de papuã em soja cujos custos de controle compensariam as perdas no rendimento de grãos seria de 33 plantas $/ \mathrm{m}^{2}$.

\section{CONCLUSÕES}

1. O incremento da cobertura do solo com palha de aveia-preta reduz de forma exponencial a infestação de $B$. plantaginea.

2. Altos níveis de palha na superfície do solo aumentam o rendimento de soja quando infestada com $B$. plantaginea.

3. O rendimento da cultura de soja não é afetado por níveis de palha de até 10,5 t/ha na ausência de plantas daninhas.

\section{AGRADECIMENTOS}

Aos Drs. Paulo Silva e Enio Marchezan, pelas sugestões acerca do texto; aos Srs. Cléo Carolo e Eduardo Manjabosco, pelo apoio técnico; à CAPES, CNPq, FAPERGS e ao convênio FAURGSMONSANTO, pelo apoio financeiro.

\section{REFERÊNCIAS}

BROWNE, R.H. On visual assessment of the significance of a mean difference. Biometrics, Alexandria, v.35, n.3, p.657-665, 1979.

COUSENS, R. A simple model relating yield loss to weed density. Annals of Applied Biology, Warwickshire, v.107, n.2, p.239-252, 1985.

ESPIRITO SANTO, F.R.C. Distribuição de óxidos de Fe em uma catena de solos derivados de granito da região fisiográfica da Depressão Central do Estado do Rio Grande do Sul. Porto Alegre : UFRGS, 1988. 141p. Dissertação de Mestrado.

FLECK, N.G. Interferência de papuã (Brachiaria plantaginea) com soja e ganho de produtividade obtido através do seu controle. Pesquisa Agropecuária Gaúcha, Porto Alegre, v.2, n.1, p.63-68, 1996.

KISSMANN, K.G. Plantas infestantes e nocivas. São Paulo : BASF, 1991. v.1, 608p.

ROMAN, E.S. Effect of cover crops on the development of weeds. In: INTERNATIONAL WORKSHOP ON CONSERVATION TILLAGE SYSTEMS, 1990, Passo Fundo. Proceedings. Passo Fundo: CIDA/Embrapa-CNPT, 1990. p.218-230.

SALTON, J.C.; MIELNICKZUK, J. Relações entre sistemas de preparo, temperatura e umidade de um podzólico vermelho escuro de Eldorado do Sul (RS). Revista Brasileira de Ciência do Solo, Campinas, v.19, n.2, p.313-319, 1995.

STOLLER, E.W.; HARRISON, S.K.; WAX, L.M.; REGNIER, E.E.; NAFZIGER, E.D. Weed interference in soybeans (Glycine max). Reviews of Weed Science, Champaign, v.3, p.155-181, 1987.

THEISEN, G. Influência de palha de aveia preta em papuã (Brachiaria plantaginea (Link) Hitch.) e seu impacto em soja. Porto Alegre : UFRGS, 1998. 87p. Dissertação de Mestrado.

VIDAL, R.A.; BAUMAN, T.T. Surface wheat (Triticum aestivum) residues, giant foxtail (Setaria faberi), and soybean (Glycine max) yield. Weed Science, Champaign, v.44, n.4, p.939-943, 1996.

VOLL, E.; GAZZIERO, D.L.P.; KARAM, D. Dinâmica de populações de Brachiaria plantaginea (Link) Hitch. sob manejos de solo e de herbicidas. 2. Emergência. Pesquisa Agropecuária Brasileira, Brasília, v.31, n.1, p.27-35, jan. 1996

ZUllo JÚNior, J.; ARRUDA, F.B. Programa computacional para ajuste de equações em dados experimentais. Campinas : Instituto Agronômico, 1986. 23p. (Boletim Técnico, 113). 